or Mira Ceti, R.A. 2h. 13 m. D.S. $3^{\circ} 31^{\prime}$. This changes from 2 mag. to equality with a very minute companion in about 33Id. $8 \mathrm{~h}$. $4 \mathrm{~m}$., but not without some uncertainty. Its colour, according to Sir J. Herschel, is a full ruby ; I saw it so once, when about 10 mag., if it was the right star, but it was immediately clouded over : at another time, near maximum, pale yellow, without a trace of red. Flammarion also finds it by direct comparison less red than a gas flame. This tint would be an interesting object of study; but care must be taken in identification. Mira is now decreasing.

Having mentioned the head of Aries, we must recollect that $\gamma$, the smallest of the three stars, is a double, interesting as the first of these objects recorded by Hooke in 1664 , and a fine object, nearly $9^{\prime \prime}$ distant. These three stars are introduced into this diagram as guides to Triangulum just above them, where we shall find our last two objects.

', R.A. 2h. 5m., D.N. $29^{\circ} 44^{\prime}$, topaz and green, an exquisitely coloured pair, $5 \frac{1}{2}$ and 7 mags., distance $3^{\prime \prime} \cdot 5$; perhaps in slow orbital motion. We shall pick it up about $\frac{3}{4}^{\circ}$ north of $a$, a little to the east. The other is a strange phænomenon,

M 33, R.A. Ih. $27 \mathrm{~m}$., D.N. $30^{\circ} 4^{\prime}$, about $I^{\circ}$ north of $a$, and not far towards the west. Feeble as it is, it will be visible even with a very small aperture, from its great extent; fully $\frac{1}{2}^{\circ}$, or the diameter of the moon, from north to south; but on the other hand may, from want of contrast, be imperceptible with any but a very low power. The elder Herschel thought it was resolved into the minutest possible stars; but this has not been confirmed. His son and d'Arrest find a principal condensation with subordinate nuclei and nebulous tracts; the Earl of Rosse, a flocculent and spiral structure, with curved intersecting branches; a strange, incomprehensible form.

Our space will not admit of an extension of this very meagre and imperfect selection, limited for the most part, for obvious reasons, to such portions of our autumnal sky as are rapidly passing away.

T. W. WEBB

\section{AN OBSERVATORY FOR HONGKONG}

$\mathrm{W}^{\mathrm{E}}$ observe that Sir John Hennessy, the Governor of Hongkong, has succeeded in getting an item of twenty thousand dollars for an observatory and time ball passed by his Legislative Council in the estimates for the current year, in addition to a sum of ten thousand dollars voted for the same purpose last year. The advice of Major H. S. Palmer, of the Royal Engineers, has been sought by the Colonial Government, and in a valuable paper published in one of the most recent Government Gazettes, he details the advantages, imperial and local, which may be expected from a physical observatory in Hongkong. The favourable position of the island for certain observations, especially with regard to the typhoons of the China Seas, on meteorology generally, and on terrestrial magnetism, was first brought to the Governor's notice in September, I879, through the Secretary of State for the Colonies, by Dr. Warren De La Rue, as ViceChairman of the Kew Committee of the Royal Society. $\mathrm{He}$ pointed out the extreme importance of obtaining accurate records of the magnetic and meteorological conditions of the China Seas. There are at present only four observatories at which continuous observations are taken on the eastern coast of Asia and the adjacent islandsone at Batavia, in Java, supported by the Dutch Government, one attached to the Russian embassy at Peking, one at Siccawei, near Shanghai, and one at Manila. The two last are supported by the Society of Jesus. It is pointed out that Hongkong divides the distance between Siccawei and Manila, and would consequently be a most valuable acquisition to the list. The support of the Government of the Colony for a limited number of years to an observatory provided with self-recording instruments is therefore invoked. English officials and merchants abroad do not as a rule display much interest in science, and it is therefore fortunate that the gentleman at present at the head of the Government of Hongkong is one capable of appreciating the great importance of Dr. De La Rue's suggestion and of energetically carrying it out. Governor Hennessy had indeed in some sense anticipated the request, for he had, two years previously, in the first estimates which be prepared for the colony, obtained five thousand dollars from his Council for an observatory and time-ball. He entirely agreed with Dr. De La Rue's remarks, and added that the clearness of the atmosphere at certain seasons would admit of a valuable record being made of sun-spots, while the tides and varying temperature of the seas surrounding Hongkong, and the slight but frequent earthquake phenomena, would also be deserving of the attention of competent observers. A sum of between thirty and forty thousand dollars has been granted altogether for the establishment of an observatory, the chief objects of which are-

I. To determine the local time by astronomical observations, and drop a time-ball daily.

2. To obtain a series of meteorological observations with instruments of the best kinds, and to acquire information relating to the typhoons and monsoons of the China seas.

3. To obtain a series of observations in terrestrial magnetism, also with the best modern apparatus.

In his report Major Palmer addresses himself to each of these subjects separately. He recommends, we are glad to notice, that none but the best instruments should be employed, and that the observatory records should be made and published with scientific precision, and be such as to command public confidence. The meteorological departaent, he points out, besides furnishing science with valuable data from a locality well suited for the observation and collection of facts appertaining to certain phenomena of special interest, cannot fail to have a direct and practical value by affording security, by its predictions and weather-warnings, to life and property in seas navigated by vast numbers of native and foreign vessels, but subject, during four or five months of the year, to rotatory storms of appalling violence and danger. Its operations, as well as its purpose, would be twofold. There would be the systematic observation and record of the ordinary phenomena of pressure, temperature, humidity, rain, sunshine, wind, and hydrometeors, such as are usual in observatories of the first order, and observations of atmospheric electricity. The second branch would be the observation and collection, as far as possible, of facts and phenomena relating to typhoons, both for the protection of marine interests and for the purpose of contributing bit by bit to our knowledge of a subject at present but little understood. He recommends that measures should be taken to enable the director of the observatory to be placed in prompt telegraphic communication with Manila, Amoy, Shanghai, Saigon, and Singapore, as well as with the south of Japan, and indicates the steps necessary for this purpose.

As for terrestrial magnetism, the character of the rocks and soil of Hongkong, and the neighbouring promontory of Kau-lung, is not, he thinks, the most favourable that could be chosen for magnetic research, yet the position of the colony on the magnetic chart, and with respect to other places where observatories are already established, leaves no room to doubt the value of well-conducted observations.

As to the staff of the observatory, a director, Major Palmer very properly suggests, should be obtained through the Astronomer-Royal, and thinks a salary of not less than $700 l$. a year should be given. Minor officers could be obtained among the non-commissioned officers of the Ordnance Survey Companies of the Royal Engineers. The prime cost he estimates at $6300 l$., and the 
subsequent annual charge at about 2000 . It would seem therefore that we may shortly expect to find a tolerably complete and well-equipped observatory in the most eastern of our possessions. It is believed also that, with the assistance of Mr. Hart, the Inspector-General of Chinese Customs, the Government of China may be induced to establish a series of meteorological stations at various points on the seaboard of their vast territory. A perusal of Major Palmer's report leaves on our mind the impression that the Colonial Government is fortunate in being able to obtain at the present time the advice and co-operation of an officer of his ability and scientific attainments.

\section{PROBING BY ELECTRICITY $Y^{1}$}

$\mathrm{T}^{\mathrm{H}}$ $\mathrm{HE}$ instrument ${ }^{2} \mathrm{I}$ have the honour of presenting to the Academy has for its object the determination of the exact place occupied by balls of lead, fragments of shell, or metallic substances of any kind embedded in the body of a person wounded by firearms; and it may be considered as a form of the well-known induction-balance of Prof. Hughes.

This exploring instrument enables us to determine that position fur the most part with very great exactness, and that without any pain to the patient, which is not the case when we use metallic probes, which require to be brought into direct contact with the projectile.

The instrument is composed essentially of a system of two parallel flat coils partially superposed upon one another in such a manner that the edge of one is nearly over the axis of the other (Fig. I). One of these coils

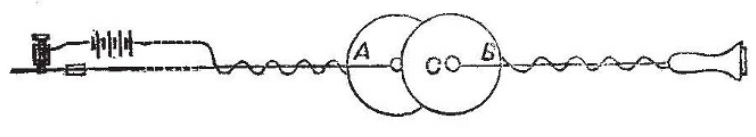

F13. I.

(A) is made of thick wire constituting a portion of the primary circuit, and the other (B) of thin wire, constituting a portion of the secondary circuit. Both coils are imbedded in a mass of paraffine placed in the interior of the wooden case furnished with a handle.

A vibratory current from a galvanic battery traverses the primary coil, and the secondary circuit includes an ordinary telephone. Under these circumstances no sound is heard from the telephone; but if we cause any metallic body to approach the part (C) common to the two coils, the silence immediately gives place to a sound the intensity of which will depend upon the nature of the metallic body, upon its form, and upon its distance. We may remark in this connection that the most favourable form that can be assumed by the projectile for which we explore, is that of a flat disk with its face parallel to the surface of the skin, and that the most unfavourable, a similar disk with its face perpendicular to the same surface.

It is difficult in practice to obtain the exact adjustment of the coils required, and it is therefore found advisable to introduce into the primary and secondary circuits

I Upon an Apparatus for Determining without Pain to the Patient the Position of a Projectile of L $=$ ad or other Metal in the Human Body. Note by Prof. Alexander Graham Bell, read by M. Antoine Breguet at the Paris Academy of Sciences. Contributed by the Author.

2 This instrument has originated from researches undertaken in the Volta Laboratory at Washington on the occasion of the sad attempt upon the life of President Garfield. This Note is preliminary to a paper which I shall publish shortly; giving a complete account of these researches. So many different persons have been kind enough to give me the benefit of their suggestions and advice concerning the method of exploration for this object, that I can only mention here the names of a few : Prof. Hughes, George M, Hopkins, Sumner Tainter, Thomas Gleeson, Dr Chichester A. Bell, Charles Fopkins, Sumner Tainter, Thomas Gleeson, Dr Chichester A. Bell, Charles John Trowbridge, J. H. C. Watts, the director of the Western Union Telegraph Costern Union York Tribune at Washington. respectively two other coils (D and E, Fig. 2) analogous to the first, but very much smaller, whose common surface can be modified by the play of a micrometer screw.

By means of this fine adjustment we are able easily to reduce the telephone to the most complete silence. It should be added that the effects obtained when a condenser (F) is introduced into the primary circuit are much inferior to those obtained without, as had been independently predicted by Prof. Rowland of Johns Hopkins University.

If we wish to ascertain the depth at which the metallic mass lies embedded this is easily ascertained if we know a priori its form, its mode of presentation, and its sub. stance. It is only necessary to adjust the apparatus to

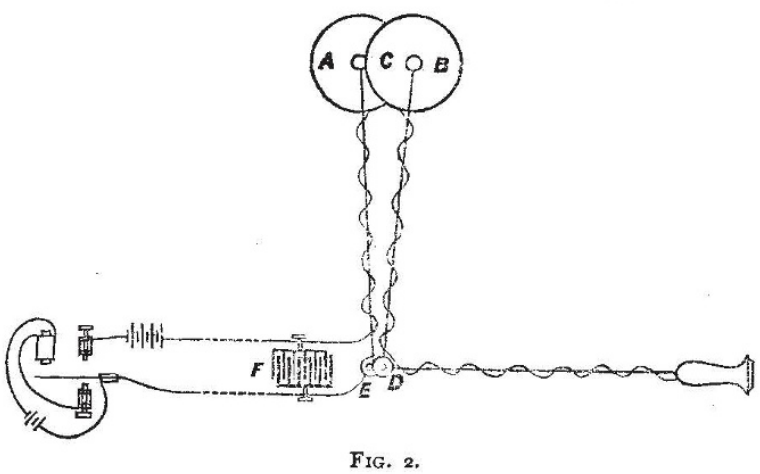

silence while it is applied to the skin, after which, removing the apparatus, we bring near it another metallic mass similar to that explored for, so as to reproduce silence anew, and the distance of this mass from the exploring instrument gives the measure which it is desired to determine.

I conclude this Note by the relation of an experiment made in the office of Dr. Frank Hamilton of New York, on October 7 last, in the presence of thirteen eminent surgeons. ${ }^{1}$ The experiment was made upon the person of Col. B. F. Clayton, wounded in 1862. The ball entered in front through the left clavicular articulation, breaking the clavicle. Doctors Swineborne and Vanderpool supposed that it was lodged under the scapula, but my apparatus demonstrated, on the contrary, that it was located in front and just below the third rib.

\section{MAGNETIC SURVEY OF MISSOURI}

IN NATURE, vol. xxiii. p. 583 , the writer presented a chart of magnetic declination which represented the results at forty-five stations in Missouri. The facts seemed to indicate a marked effect due to contour. Up to the middle of August of the past summer nothing inconsistent with this explanation was found, although the number of stations had been increased to over eighty. By that time the stations had become so numerous in Central Missouri that a more minute survey along the river bank between Jefferson City and Glasgow gave promise of affording a crucial test. It was necessary that the $8^{\circ}$ line, which bends down the river, crossing at some point east of the mouth of the Osage River, should return on the south side of the river, looking something like a reversed contour line.

What we did find was, that the $8^{\circ}$ line crosses the Missouri Valley without bending, running south-west to near the summit of the "divide" between the Osage and Missouri rivers, and then bends abruptly to the northeast, re-crossing the Missouri above Jefferson City, and

× Doctors G. H. Gardner, G. Durant, Ed. Birmingham, N. Bozeman, L. Damainville, J. N. Hinton, Francis Delagield, F. H. Hamilton, D. Cham-
berlain, Elias Marsh, J. G. Johns on, Joseph Halderson, and J. G. Allan. 